\title{
The Relationship between Nigerian Bonnylight Crude Oil-Induced Hypoglycaemia and Endogenous Serum Insulin Concentration in Male Wistar Rats: The Role of Antioxidant Vitamins $\mathrm{C}$ and $\mathrm{E}$
}

\author{
S. O. Ita ${ }^{1}$, E. O. Aluko1, T. H. Olubobokun'1, U. A. Okon'1, A. B. Antai' ${ }^{2}$ E. E. Osim ${ }^{2}$ \\ ${ }^{1}$ Department of Physiology, College of Health Sciences, University of Uyo, Uyo, Nigeria \\ ${ }^{2}$ Department of Physiology, College of Medical Sciences, University of Calabar, Calabar, Nigeria \\ Email: uloro2003@yahoo.com
}

Received 5 March 2014; revised 1 April 2014; accepted 28 April 2014

Copyright (C) 2014 by authors and Scientific Research Publishing Inc.

This work is licensed under the Creative Commons Attribution International License (CC BY).

http://creativecommons.org/licenses/by/4.0/

(c) (i)

Open Access

\begin{abstract}
The relationship between Nigerian Bonny Light crude oil (NBLCO) induced hypoglycaemia and endogenous serum insulin concentration; the role of antioxidant vitamin $C$ or $E$ supplementation was the focus of this study. Forty adult male Wistar rats were randomly divided into group I, which served as the control, group II, which was oral gavaged $6 \mathrm{ml} / \mathrm{kg}$ of NBLCO, groups III and IV, which were in addition to $6 \mathrm{ml} / \mathrm{kg}$ of NBLCO supplemented with $9 \mathrm{ml} / \mathrm{kg}$ and $1 \mathrm{mg} / \mathrm{kg}$ of vitamin E or C, respectively for 28 days. Results showed that NBLCO significantly $(p<0.05)$ lower body weight and food intake compared with control. These effects exerted by NBLCO were however significantly $(p<0.05)$ reversed by vitamin E or C supplementation. The NBLCO significantly $(p<0.05)$ reduced fasting blood glucose (FBG) when compared with control, the antioxidant vitamins supplementation significantly $(p<0.05)$ reversed the crude oil effect. The mean serum insulin level in NBLCO, vitamin E or C supplemented groups is not significantly different from the control. There was no significant correlation between FBG and fasting serum insulin concentrations in all the groups on day 28. It has been demonstrated in this study that direct oral ingestion of crude oil (NBLCO) could reduce food intake, body weight and cause hypoglycemia; the hypoglycemia may not be a function of serum insulin concentration. Interestingly, the hazardous effects of NBLCO could be ameliorated with antioxidant vitamin $C$ or $E$ supplementation.
\end{abstract}

*Corresponding author.

How to cite this paper: Ita, S.O., et al. (2014) The Relationship between Nigerian Bonnylight Crude Oil-Induced Hypoglycaemia and Endogenous Serum Insulin Concentration in Male Wistar Rats: The Role of Antioxidant Vitamins C and E. American Journal of Molecular Biology, 4, 81-88. http://dx.doi.org/10.4236/ajmb.2014.42010 


\section{Keywords}

\section{Nigerian Bonny Light Crude Oil; Hypoglycaemia; Serum Insulin Concentration; Antioxidant Vitamins}

\section{Introduction}

The prevalence of crude oil spillages and the attendant contamination is increasing rapidly in the Niger Delta region of Nigeria with a resultant unrestricted exposure of animals including humans [1] [2] in the environment, as well as the ingestion of petroleum-contaminated food substances ranging from water to aquatic organisms and crops, have been reported to negatively affect animals' health in diverse ways [3]-[8].

Most reports on the toxicological effects of crude oil in relation to its refined products on health of organisms have centered much on the inhalation of petroleum fumes with little or no attention on oral ingestion. It is therefore pertinent to note that most of the rural dwellers that indulge in the unorthodox folklore medicine actually consume crude oil by oral ingestion. Apart from this sub-lethal effect from direct crude oil ingestion, crude oil can also be indirectly incorporated into the food chain [9] by way of contamination from spillages and other sources, which can result in spectrum of toxic effects. These may include inflammation, derangement in glucose metabolism, lipid profile with ultimate impairment of health status [10] [11]. Most importantly, hypoglycaemic effect of crude oil in experimental animals is widely reported in literature with diverse hypotheses on the possible mechanism(s) [11]-[14]. So far, there has not been any reported role of insulin on glucose metabolism associated with crude oil administration. In the light of this, investigation on the relationship between NBLCO-induced hypoglycaemia and endogenous serum insulin concentration in male Wistar rats, as well as the role of antioxidant vitamins $\mathrm{C}$ and $\mathrm{E}$ supplementation were undertaken.

\section{Materials and Method}

\subsection{Chemicals}

The Crude petroleum was obtained from the EXXON/MOBIL laboratory Eket, Nigeria. The chemical used was chloroform from BDH Chemicals Ltd, (Poole, England).

\subsection{Experimental Animals}

Mature male Wistar albino rats weighing between 130 - $135 \mathrm{~g}$ were obtained from the animal house of the Faculty of Pharmacy, University of Uyo, Nigeria and were kept in a well-ventilated experimental section in the animal house for fourteen (14) days to acclimatize. The animals were allowed food and water ad libitum. After the acclimatization period, the animals were weighed, their fasting blood glucose levels (FBG) taken, before the commencement of experimental treatment.

\subsection{Experimental Design and Treatment of Animals}

A total of forty (40) adult male Wistar albino rats were randomly divided into four groups, group I served as control. It was experimentally designed thus; group II, the crude oil group (CO) was oral gavaged $6 \mathrm{ml} / \mathrm{kg}$ of Nigerian Bonny Light Crude Oil (NBLCO) according to the dose described by Eyong et al. [15]. Groups III and IV were in addition to $6 \mathrm{ml} / \mathrm{kg}$ of Nigerian Bonny Light Crude Oil (NBLCO) supplemented with $9 \mathrm{ml} / \mathrm{kg}$ and 1 $\mathrm{mg} / \mathrm{kg}$ of vitamin $\mathrm{E}$ or C respectively. In all cases, the dose, which was based on the rat's most recently recorded body weight, was applied daily.

The rats in all treated groups were repeatedly exposed by oral gavaged to NBLCO (CO), NBLCO + vitamin E $(\mathrm{CO}+$ Vit. E) and NBLCO + vitamin C (CO + Vit. C) as earlier stated for 28 days. Rats in the control group were similarly oral gavaged with $10 \mathrm{ml} / \mathrm{kg}$ of normal saline as control vehicle for the same 28 days. The weight of animals and glucose levels were taken on day 1, 7, 14, 21 and 28, before the animals were sacrificed.

\subsection{Collection of Blood Sample for Analysis}

After twenty eight (28) days of administration, the rats were again weighed and anaesthetised with chloroform 
soaked in swap of cotton wool in a desiccator. A $(5 \mathrm{ml})$ sterile syringe with needle was used for collection of blood from the heart, by cardiac puncture. The blood sample was transferred into properly labeled sterile sample bottles.

The blood samples were spun with table top centrifuge (RM-12 Micro centrifuge, REMI, England) at $3000 \mathrm{rpm}$ for 10 minutes. Then the serum was separated gently with the help of micropipette and stored in labeled eppendrof tubes at $-20^{\circ} \mathrm{C}$ until assayed for serum chemistry.

\subsection{Estimation of Food Intake}

These animals were kept singly in clean plastic cages. They were given rat chow (Vital feeds, Grand Cereals Ltd, Jos). The food intake was determined by measuring the initial amount of food (in gramme) presented to the rats and amount by weight of left-over after 24 hours. The amount of left-over was subtracted from the initial weight to obtain the amount presumably consumed by the rats.

\subsection{Estimation of Fasting Blood Glucose (FBG)}

Fasting blood glucose was determined from drops of blood from cut tip of rat tail using one-touch life-scan blood glucose meter (USA). This was done on the first day of experiment, thereafter was done on weekly basis and on the day of sacrifice blood sample collected directly from the heart was used for glucose determination.

\subsection{Estimation of Serum Insulin Concentration}

The DRG insulin enzyme immunoassay kit (Germany) was used for the determination of insulin in serum.

\subsection{Statistical Analysis}

Values of the biochemical assays were expressed as mean ( \pm ) standard error (SE) and were statistically analysed with SPSS 15.0 version using one way analysis of variance and results were further subjected to post hoc test using Least Square Deviation (LSD). $p<0.05$ was considered to be significant.

\section{Results}

\subsection{Evaluation of Changes in Body Weight}

The initial body weight, final body weight and weight change in the control, CO, COE and COC rats are as presented in Table 1. The results showed that Nigerian Bonny Light crude oil significantly reduced body weight compared with control $(p<0.05)$. However, the body weight reduction exerted by NBLCO was significantly ( $p$ $<0.05$ ) reverse by vitamin $\mathrm{E}$ or $\mathrm{C}$ supplementation.

\subsection{Evaluation of Weekly Food Intake in Control and Treatment Rats}

The weekly food intakes in the control and treatment groups are presented in Figure 1. Results showed that Nigerian Bonny Light crude oil (CO) significantly $(p<0.05)$ reduced food intake when compared with the control. Vitamin E or C supplementation however significantly $(p<0.05)$ increased food intake compared with CO group but not significantly different from control.

\subsection{Weekly Fasting Blood Glucose of Control and Treatment Rats}

The Nigerian Bonny Light crude oil (CO) significantly $(p<0.05)$ reduced fasting blood glucose (FBG) when compared with control. Vitamin E or C supplementation significantly $(p<0.05)$ reversed this effect compared with CO group, this effect was not significantly different from control, as presented in Figure 2.

\subsection{Serum Insulin Concentration ( $\mu \mathrm{IU} / \mathrm{mL})$ and Fasting Blood Glucose on Day 28}

Figure 3 is a representation of serum insulin concentration and fasting blood glucose for the control and treatment rats taken on day 28. The mean serum insulin level in CO group was not significantly different from the control. Similarly, serum insulin levels in groups supplemented with vitamin E or C were not significantly different from CO group. The Nigerian Bonny Light crude oil (CO) significantly $(p<0.05)$ reduced fasting blood 
Table 1. Comparison of change in body weight of the control and treatment rats.

\begin{tabular}{cccc}
\hline Groups & Initial Weight $(\mathrm{g})$ & Final Weight $(\mathrm{g})$ & Weight Difference \\
\hline Control & $130.46 \pm 0.42$ & $137.11 \pm 0.40$ & $6.65 \pm 0.64$ \\
CO & $130.67 \pm 0.27$ & $123.49 \pm 0.23$ & $-7.18 \pm 0.28^{\mathrm{a}}$ \\
COE & $131.70 \pm 0.84$ & $148.63 \pm 0.53^{\mathrm{a}, \mathrm{b}}$ & $16.93 \pm 0.95^{\mathrm{a}, \mathrm{b}}$ \\
COC & $130.90 \pm 0.53$ & $144.21 \pm 0.23^{\mathrm{a}, \mathrm{b}, \mathrm{c}}$ & $13.31 \pm 0.62^{\mathrm{a}, \mathrm{b}, \mathrm{c}}$ \\
\hline
\end{tabular}

Legend: ${ }^{\mathrm{a}} p<0.05$ vs Control; ${ }^{\mathrm{b}} p<0.05$ vs $\mathrm{CO} ;{ }^{\mathrm{c}} p<0.05$ vs $\mathrm{COE}$; $\mathrm{CO}=$ crude oil; $\mathrm{COE}=$ crude oil plus vitamin $\mathrm{E}$; $\mathrm{COC}=$ crude oil plus vitamin $\mathrm{C}$.

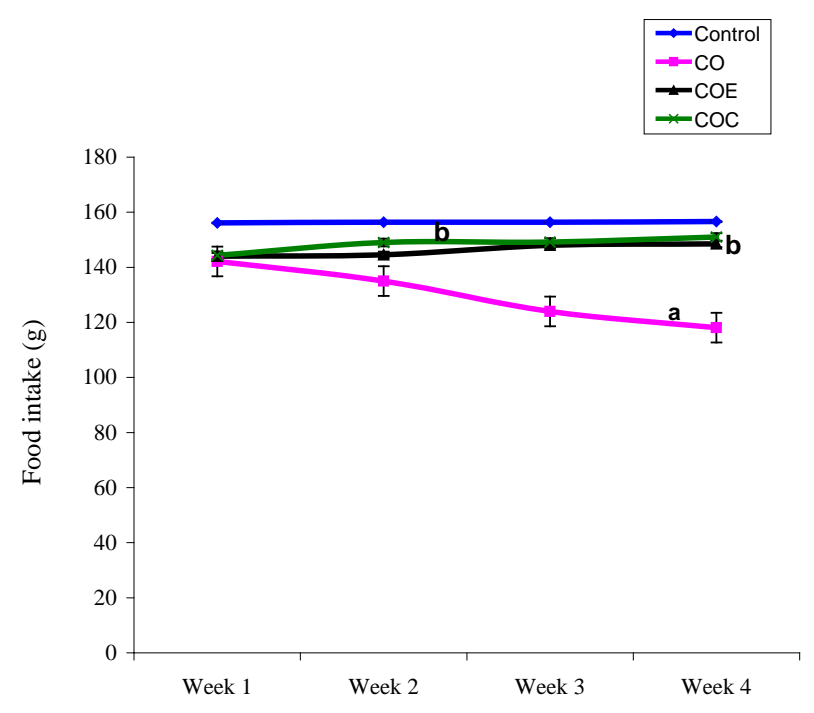

Figure 1. Comparison of mean weekly food intake in control and NBLCO treated rats. Values are mean $+\mathrm{SEM}, \mathrm{n}=10$. (a) $p$ $<0.05$ vs control, (b) $p<0.05$ vs CO.

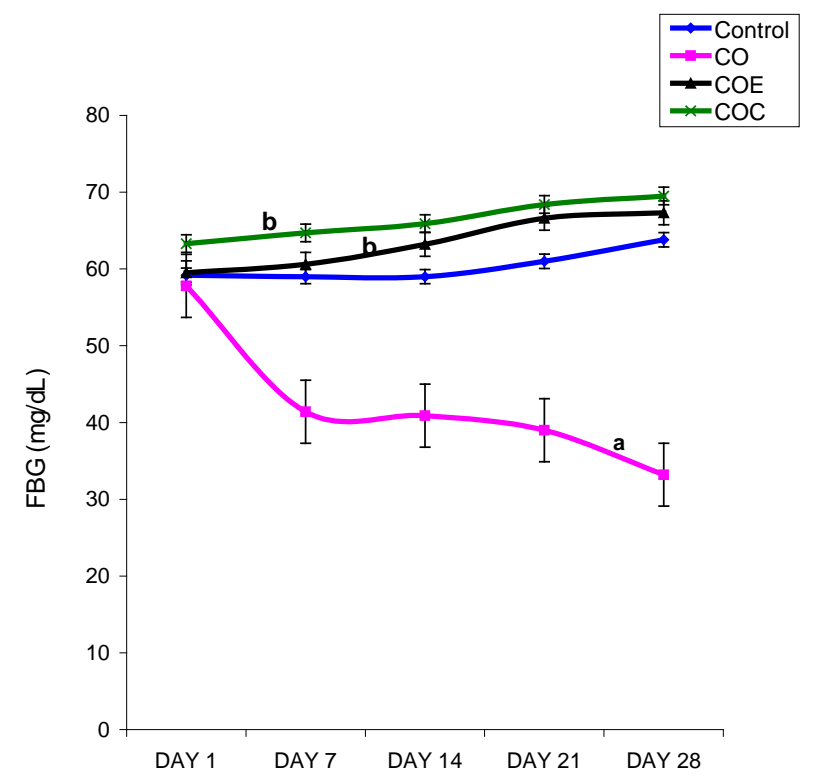

Figure 2. Comparison of mean weekly food intake in control and NBLCO treated rats. Values are mean + SEM, $\mathrm{n}=10$. (a) $p$ $<0.05$ vs control, (b) $p<0.05$ vs CO. 

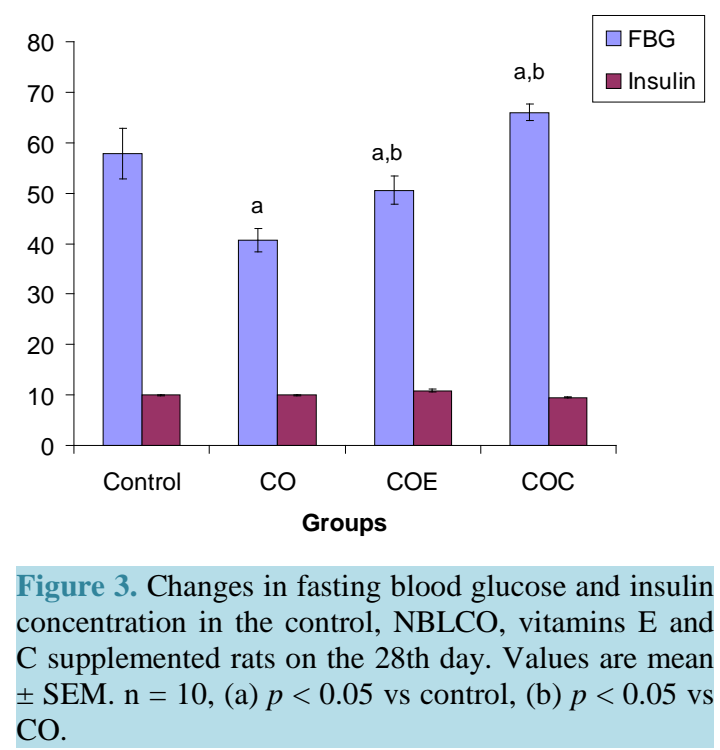

glucose (FBG) compared with control on day 28, but vitamin E or C supplementation significantly $(p<0.05)$ increased FBG when compared with CO and control groups.

\subsection{Relationship between Fasting Blood Glucose and Plasma Insulin on the 28th Day}

The correlation between fasting blood glucose (FBG) and fasting serum insulin levels on day 28 of treatment was determined for the control and various treatment groups as presented in Figure 4.

There was no significant correlation between FBG and fasting serum insulin concentrations in all the groups on day 28.

\section{Discussion}

Ingestion of crude oil causes a wide spectrum of toxicological effects, as well as biochemical and physiological dysfunctions that may constitute serious health hazards and threat to humanity; such is evidenced in this study.

Nigerian Bonny Light crude oil significantly reduced food consumption and body weight in the treatment rats throughout the experimentation. Crude petroleum contamination can have severe consequences on the health of organisms including humans. Stress, fright, hypothermia and exhaustion are some physical manifestations that may be associated with oil spills [16]; it is also reported that crude oil consumption can induce a significant decrease in body and organ weight [17]. It was not surprising when the rats in this study showed visible signs of Nigerian Bonny Light Crude Oil (NBLCO) toxicity, which included anorexia and weakness, which corroborate a similar report on mussels where xenobiotics including polycyclic aromatic hydrocarbon (PAH) were reported to significantly reduce the feeding rate of mussels [18]. These observed physical signs could probably have been due to damage and depletion of bodily proteins as well as interference with protein synthesis by free radicals generated by NBLCO. That such damages could be associated with oxidant radical species generated by NBLCO during the course of its metabolism is supported by the fact that antioxidant therapy (Vitamin E or C) significantly corrected these abnormalities in body weight and the amount of food consumed. It can be speculated that polyaromatic hydrocarbons (PAHs) in crude oil in addition to its other constituents can as well affect the physiologic parameters that are directly related to the nutrient status of an organism.

The concentration of oxidants in the body can be elevated by xenobiotic insults such as crude oil [18] as in this case, NBLCO. At high concentrations, oxidants are reported to have the potentials to ultimately damage all major cellular constituents [19].

Antioxidants are potentially protective agents that may help guard against oxidation as evidenced in this study by the significant reversal of the hazardous effects of NBLCO with antioxidant vitamin E or C supplementation. This corroborate previous findings that potentially damaging oxidative stress is kept in check by endogenous cellular antioxidant defense mechanisms, which include antioxidant enzymes (Superoxide dismutase, catalase 


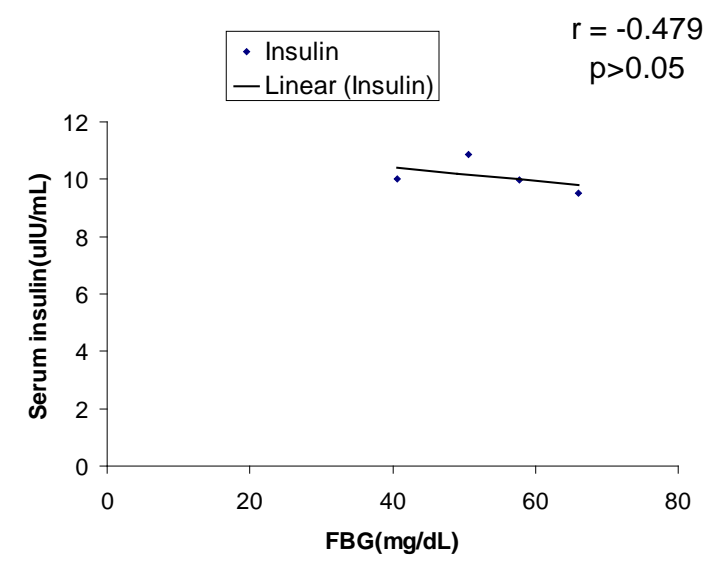

Figure 4. Relationship between fasting blood glucose (FBG) and serum insulin concentration in all groups on the 28th day.

and glutathione peroxidase), antioxidant micro-elements, and nutrient-derived antioxidant small molecules (Vitamins A, C, E, carotenes, flavonoids, glutathione) [20].

This study confirmed the hypoglycemic effect of crude oil ingestion reported in experimental animals [12] [13] and yellow-legged gulls [11]. Thus, the results of this study support the conclusion that petroleum products are able to induce a decrease in circulating glucose levels in experimental animals, not only after long-term exposures [14], but also after short-term episodes of ingestion as postulated by Alonso-Alvarez and co-workers [14]. Other than the link with the alterations in the level of lipid peroxidation and activities of superoxide dismutase which have been reported in hypoglycemic rats [21]-[23], consumption of crude oil contaminated feed is said to induce lipid peroxidation in rats [3] [4], no other mechanism has been suggested. It will not be out of place to speculate that oxidative stress like NBLCO may have caused the generation of ROS [24] [25], which in turn stimulates increased cellular utilization of glucose for energy coupled with low food intake with resultant low blood glucose level, this is more so because ROS has been reported to increase glucose uptake in skeletal muscles [26]-[28]. Lending support to the implication of ROS is the result from the antioxidant groups, vitamin C or E which completely reversed the hypogylcaemia induced by NBLCO in this study.

Similar alterations in oxygen consumption, tissue glycogen and glucose levels following exposure of fish to crude oil fractions have been reported [29], but no reason was adduced for the alterations.

The results of this study showed significant decrease in blood glucose level, which is corroborated by earlier work of Alonso-Alvarez, et al. [14] who reported reduced blood glucose levels in seabirds sampled in oiled areas. Although, contradiction exists in literature, for example Golet et al., [10] that reported higher glucose levels in blood from pigeon guillemots (Cepphus columbia) sampled in areas affected by the Exxon-Valdez oil spill, where they attributed the hyperglycemic effect to increased adrenal response reflected by high level of circulating corticosterone, earlier authors have reported decreased adrenocortical response in oil seabirds [30]. However, the result of this study is in agreement with crude oil hypoglycemic effect hypothesis. The exact specific toxicant in the crude oil and mechanism that is responsible for the hypoglycemia is not clear. Alonso-Alvarez and his co-workers [14] suggested polycylic aromatic hydrocarbons (PAHs) to be responsible for the decrease in glucose level even though they acknowledged that crude oil contains other toxic compounds that may possibly have contributed to the observed effects. It can be argued that the hypoglycemia reported in this study is purely a function of NBLCO toxicity, as corresponding low food intake and lower body mass have also been reported. Atherogenic potentials of NBCO have been reported by Ita and co-workers (2013) [31], these workers emphatically stressed that in spite of these potentials that NBLCO significantly reduced triglyceride levels in rat. They argued that the body tissues would have resorted to triglyceride as an alternative energy substrate in the phase of hypoglycermia, accounting for the significantly low triglyceride they reported [31]. These reductions may adversely affect glycogenic tissues and enzymes in the rats.

The non-elevated fasting insulin levels recorded in NBLCO-treated group may suggest inadequate secretion due to beta cell dysfunction or beta cell damage [32]. Reactive oxygen species (ROS) are known to damage body tissues via lipid peroxidation [4]-[6] [24] [25] [33], and the pancreas may not be an exception. Since there 
was no positive correlation between serum insulin and blood glucose, it could be suggested that the hypoglycaemia induced by NBLCO treatment is independent of circulating insulin concentration.

The direct administration of NBLCO through oral gavage to rats reduces food consumption and consequently resulted in weight loss in comparison with control throughout the period of administration. It appeared that the hypoglycemia recorded was a direct function of NBLCO as serum insulin did not show any significant increase. This might also suggest possible injury to the glucogenic organs like the liver and kidney. Interestingly, vitamin $\mathrm{C}$ or E supplementation ameliorated the aforementioned effects.

It has been demonstrated in this study that direct oral ingestion of crude oil (NBLCO) could reduce food intake, body weight and cause hypoglycemia, and that the hypoglycemia is not a function of plasma insulin concentration. And the hazardous consequences of ingestion of NBLCO could be ameliorated with antioxidant vitamin C or E supplementation.

\section{References}

[1] Akpofure, E.A., Efere, M.I. and Ayawei, P. (2000) Petroleum Induced Free Radical Toxicity in African Catfish (Clarias gariepinus). Fish Physiology and Biochemistry, 29, 27-103.

[2] Daniel-Kalio, L.A. and Braide, S. (2002) The Impact of Accidental Spill on Cultivated Vegetation in a Wetland Area of Niger Delta, Nigeria. AMIO, 31, 441-442.

[3] Anozie, O.I. and Onwurah, I.N.E. (2001) Toxic Effect of Bonny Light Crude Oil in Rat after Ingestion of Contaminated Diet. Nigeria Journal of Biochemistry and Molecular Biology, 16, 103-108.

[4] Khan, A.A., Coppock, R.W. and Schuler, M.M. (2001) Effect of Multiple Exposures of Small Doses of Pembina Cardium Crude Oil and Diesel in Rats. Archives of Environmental Contamination and Toxicology, 40, 418-424. http://dx.doi.org/10.1007/s002440010192

[5] Downs, C.A., Shigenska, G., Fauth, J.E, Robinson, C.E. and Huang, A. (2002) Cellular Physiological Assessment of Bivalves after Chronic Exposure to Spilled Exxon Valdes Crude Oil Using a Novel Molecular Diagnostic Biotechnology. Environmental Science Technology, 36, 2987-2993. http://dx.doi.org/10.1021/es011433k

[6] Achuba, F.I. and Osakwe, S.A. (2003) Petroleum Induced Free Radical Toxicity in African Catfish. Fish Physiology and Biochemistry, 29, 97-103. http://dx.doi.org/10.1023/B:FISH.0000035905.14420.eb

[7] Ita, S.O. and Udofia, U.A. (2011) Comparative Study of Some Haematological Parameters in Rats Following Ingestion of Crude Oil (Nigerian Bonny Light), Petrol, Kerosene and Diesel. Asian Journal of Biological Sciences, 4, 498-505. http://dx.doi.org/10.3923/ajbs.2011.498.505

[8] Ita, S. O., Udofia, U.A., Udokang, N.E. and Okon, U.A. (2011) Comparative Osmotic Fragility in Rats Following Ingestion of Crude Oil (Nigerian Bonny Light), Petrol, Kerosene and Diesel. International Journal of Current Trends in Science and Technology, 2, 362-331.

[9] Yadau, J. S. and Seth, N. (2001) Cytogenetical Damage in Petrol Pump Workers. IJHG, 1, 145-150.

[10] Golet, G.H., Seiser, P.E. Mcguire, A.D., Roby, D.D., Fischer, J.B., Kuletz, K.J., Irons, D.B., Dean, T.A., Jewett, S.C. and Newman, S.H. (2002) Long-Term Direct and Indirect Effects of the Exxon Valdez Oil Spill on Pigeon Guillemots in Prince William Sound, Alaska. Marine Ecological Progress and Services, 241, 287-304. http://dx.doi.org/10.3354/meps241287

[11] Alonso-Alvarez, C., Munilla, I., López-Alonso, M. and Velando, A. (2007a) Sublethal Toxicity of the Prestige Oil Spill on Yellow-Legged Gulls. Environmental International, 54, 7733-7781.

[12] Rebar, A.H., Lipscomb, T.P., Harris, R.K. and Mallachey, B.E. (1995) Clinical and Clinical Laboratory Correlates in Sea Otters Dying Unexpectedly in Rehabilitation Centre Following the Exxon Valdez Oil Spill. Veterinary Pathology, 32, 346-350. http://dx.doi.org/10.1177/030098589503200402

[13] Newman, S.H., Anderson, D.W., Ziccardi, M.H., Trupkiewicz, J.G., Tseng, F.S., Christopher, M.M. and Zinkl, J.G. (2000) An Experimental Soft-Release of Oil-Spill Rehabilitated American Coots (Fulica americana): II. Effects on Health and Blood Parameters. Environmental Pollution, 107, 295-304. http://dx.doi.org/10.1016/S0269-7491(99)00171-2

[14] Alonso-Alvarez, C., Pérez, C. and Velando, A. (2007) Effects of Acute Exposure to Heavy Fuel Oil from the Prestige Spill on a Seabird. Aquatic Toxicology, 84, 103-110. http://dx.doi.org/10.1016/j.aquatox.2007.06.004

[15] Eyong, E.U., Umoh, I.B., Ebong, P.E., Eteng, M.U., Antai, A.B. and Akpa, A.O. (2004) Haematoxic Effects Following Ingestion of Nigerian Crude Oil and Crude Oil Polluted Shellfish by Rats. Nigerian Journal of Physiological Sciences, 19, 1-6.

[16] Briggs, K.T., Yoshida, S.H. and Gershwin, M.E. (1996) The Influence of Petrochemicals and Stress on the Immune 
System of Seabirds. Regulatory Toxicology and Pharmacology, 23, 145-155. http://dx.doi.org/10.1006/rtph.1996.0036

[17] Alonso-Alvarez, C. and Ferrer, M. (2001) A Biochemical Study about Fasting, Sub-Feeding and Recovery Processes in Yellow-Legged Gulls. Physiological and Biochemical Zoology, 74, 703-713.

[18] Di Toro, D.M., McGrath, J.A. and Hansen, D.J. (2000) Technical Basis for Narcotic Chemicals and Polycyclic Aromatic Hydrocarbon Criteria. I. Water and Tissue. Environmental Toxicology and Chemistry, 19, 1951-1970. http://dx.doi.org/10.1002/etc.5620190803

[19] Valko, M., Leibfritz, D., Moncol, J., Cronin, M., Mazur, M. and Tesler, J. (2007) Free Radicals and Antioxidants in Normal Physiological Functions and Human Disease. International Journal of Biochemistry and Cell Biology, 39, 4484. http://dx.doi.org/10.1016/j.biocel.2006.07.001

[20] Sardesai, V.M. (1995) Role of Antioxidants in Health Maintenance. Nutrition in Clinical Practice, 10, 19-25. http://dx.doi.org/10.1177/011542659501000119

[21] Koska, J., Blazicekl, P., Markol, M., Grnal, J.D., Kvetnansky, R. and Vigas, M. (2002) Insulin, Catecholamines, Glucose and Antioxidant Enzymes in Oxidative Damage during Different Loads in Healthy Humans. Physiological Research, 49, 95-100.

[22] Patockova, J., Marhol, P., Turnova, E., Krsiak, M., Rokyta, R., Stipeck, S., Crikorska, J. and Andel, M. (2003) Oxidative Stress in the Brain Tissue of Laboratory Mice with Acute Post-Insulin Hypoglycaemia. Physiological Research, 52, 131-135.

[23] Singh, P., Jain, A. and Kaur, G. (2004) Impact of Hypoglycemia and Diabetics on CNS: Correlation of Mitochondrial Oxidative Stress with DNA Damage. Molecular and Cellular Biochemistry, 260, 153-159.

[24] Halliwell, B. (1992) Reactive Oxygen Species and the Central Nervous System. Journal of Neurochemistry, 59, 16091623. http://dx.doi.org/10.1111/j.1471-4159.1992.tb10990.x

[25] Liu, J. and Mori, A. (1994) Involvement of Reactive Oxygen Species in Emotional Stress: A Hypothesis Based on the Immobilizations Stress-Induced Oxidative Damage and Antioxidant Defense Changes in Rat Brain and the Effect of Antioxidant Treatment with Reduced Glutathione. International Journal of Stress Management, 1, 249-263. http://dx.doi.org/10.1007/BF01857992

[26] Higaki, Y., Hirshman, M.F., Fujii, N. and Goodyear, L.J. (2001) Nitric Oxide Increases Glucose Uptake through a Mechanism that Is Distinct from the Insulin and Contraction Pathways in Rat Skeletal Muscle. Diabetes, 50, 241-247. http://dx.doi.org/10.2337/diabetes.50.2.241

[27] Higaki, Y., Mikami, T., Fujii, N., Hirshman, M.F., Koyama, K., Seino, T., Tanaka, K. and Goodyear, L.J. (2008) Oxidative Stress Stimulates Skeletal Muscle Glucose Uptake through a Phosphatidylinositol 3-Kinase-Dependent Pathway. American Journal of Physiology—Endocrinology and Metabolism, 294, 889-897. http://dx.doi.org/10.1152/ajpendo.00150.2007

[28] Jensen, T.E., Schjerling, P., Viollet, B., Wojtaszewski, J.E. and Richter, E.A. (2008) AMPK $\alpha 1$ Activation Is Required for Stimulation of Glucose Uptake by Twitch Contraction, but Not by $\mathrm{H}_{2} \mathrm{O}_{2}$, in Mouse Skeletal Muscle. PLoS ONE, 3, Article ID: e2102. http://dx.doi.org/10.1371/journal.pone.0002102

[29] Omoregie, E., Ufodike, E.B.C. and Onwuliri, L.O. (1997) Effect of Water Soluble Fractions of Crude Oil on Carbohydrate Reserves of Oreochromic niloticus. Journal of Aquatic Science, 12, 1-8.

[30] Gorsline, J. and Holmes, W.N. (1982) Suppression of Adrenocortical Activity in Mallard Ducks Exposed to PetroleumContaminated Food. Archives of Environmental Contamination and Toxicology, 11, 497-502. http://dx.doi.org/10.1007/BF01056078

[31] Ita, S.O., Olubobokun, T.H., Benson, E.A., Antai, A.B. and Osim, E.E. (2013) Anti-Atherogenic Potentials of Vitamin C or E Administration against Ingested Nigerian Bonny Light Crude Oil (NBLCO) in Male Wistar Rats. E3 Journal of Medical Research, 2, 117-122.

[32] Mack, R., Skurnick, B., Sterling-Jean, Y., Pedra-Nobre, M. and Bigg, D. (2004) Fasting Insulin Levels as a Measure of Insulin Resistance in American Blacks. The Journal of Applied Research, 4, 90-94.

[33] Lam, H.R., Ostergaard, G., Guo, S.X., Ladefoged, O. and Bondy, S.C. (1994) Three Weeks' Exposure of Rats to Dearomatized White Spirit Modifies Indices of Oxidative Stress in Brain, Kidney, and Liver. Biochemistry and Pharmacology, 47, 651-657. http://dx.doi.org/10.1016/0006-2952(94)90127-9 